\title{
Effects of undernutrition by rearing in large litters on acquisition and memory of active-avoidance learning in mice
}

\author{
Z. MICHAEL NAGY \\ Bowling Green State University, Bowling Green, Ohio \\ and \\ KENNETH J. PORADA \\ Heidelberg College, Tiffin, Ohio
}

\begin{abstract}
To determine the effects of early undernutrition on learning and long-term memory, Swiss mice were cross-fostered randomly at birth to produce litter sizes of 6 and 16, thereby providing "normally nourished" and "undernourished" conditions. At 28 days of age, the pups were housed in groups of 3 and 4, with ad-lib access to food and water until testing began at 60 days of age. Each mouse received 50 active-avoidance training trials daily for 14 consecutive days. Retention testing began 14 days after the end of original training and consisted of 50 trials daily for 5 days. Overall, mice reared in large litters suffered deficits in learning but not in long-term memory.
\end{abstract}

Increasing evidence indicates that undernutrition or malnutrition during early development of lower animals, particularly during the "brain growth spurt" (Dobbing, 1968), can have permanent effects upon the growth, physiology, and biochemistry of the brain (Nowak \& Munro, 1977; Shoemaker \& Bloom, 1977; Wiggins, Fuller, \& Enna, 1984). Although the validity of some findings in early neurohistological studies has been challenged recently (primarily on the basis of inadequate or outdated methodologies, questionable statistical analyses, and small sample sizes; Bedi, 1984), it is well documented that nutritional deficiencies experienced during the suckling and/or gestation period, even when followed by extended periods of nutritional rehabilitation, can have permanent effects on whole brain and body growth (Bedi, 1987; Burns, 1984) and probably more selective effects on other physiological and biochemical parameters of the adult brain (Herschkowitz, 1989; Jordan \& Clark, 1983; Katz \& Davies 1982; Salbego \& Souza, 1986).

One of the puzzling and extremely frustrating outcomes of much research directed toward ascertaining the functional consequences of such deficiencies in brain and body growth has been the failure to find consistent effects on adult behavior that can be attributed definitively to early undernutrition (Katz, 1980; Smart, 1977). Such inconsistent behavioral data have led some researchers to suggest that the different techniques commonly used to produce undernourished animals (see Crnic, 1976, for a review of techniques) also alter the psychosocial interactions of the mother-pup and pup-pup, and it may well be that these

Correspondence should be addressed to Z. Michael Nagy, Department of Psychology, Bowling Green State University, Bowling Green, $\mathrm{OH} 43403$. changes in social interactions are affecting later adult behavior (Crnic, 1976; Fleischer \& Turkewitz, 1979a, 1979b; Levine \& Wiener, 1976; Plaut, 1970). Others have argued that the differential behaviors that are seen following early undernutrition have been caused by changes in motivation or "emotionality," and thus are performance, rather than learning, factors (Levitsky \& Barnes, 1970; Smart \& Dobbing, 1977; Smart, Whatson, \& Dobbing, 1975).

Smart $(1977,1984,1986)$ comprehensively reviewed the undernutrition literature employing lower animals and noted the directions of results and species used. Although his recent reviews indicate an increase in the number of experiments in which behavioral differences were found that might be attributed to early undernutrition, it is quite evident that the findings continue to be inconsistent for many learned behaviors. For example, of 31 experiments with rats in which active-avoidance learning in adulthood following early undernutrition and subsequent rehabilitation feeding were examined, in 8 , the normally nourished group was found to be superior; in 6, the previously undernourished group was found to be superior; and in 17, no significant differences caused by early nutrition (Smart, 1986) were found. In addition to the generally inconsistent behavioral findings, Smart (1986) also noted that relatively few species have been investigated, with $85 \%$ of the published papers employing rats as subjects. However, the species with the most consistent behavioral results to date, the mouse, has been little investigated. Although several reports have indicated consistent long-term deficiencies in physiological, biochemical, and behavioral measures in the Swiss mouse caused by early undernutrition by rearing in large litters (Castellano \& Oliverio, 1976; Leathwood, 1978; Leathwood, Bush, Berent, \& Mauron, 1974), Smart (1977) has cautioned that half of the mouse experi- 
ments were performed in only one laboratory, and most employed the same mouse strain and two-way activeavoidance task.

The purpose of the present study was to extend, in two ways, the findings of earlier mouse studies with the twoway active-avoidance task: First, long-term memory was tested, since it has been little investigated as of yet and has been suggested as one of the aspects of learning in previously undernourished animals that are most deserving of further investigation (Smart, 1986). Second, female mice were also tested, since previous research with mice has not included females, whereas early undernutrition research with rats has not tested females often because they appear to be less affected than males by early undernutrition (Williams, Tanner, \& Hughes, 1974).

\section{METHOD}

\section{Subjects}

Subjects were 80 Swiss-Webster albino mice (Mus musculus), divided equally between genders, born and reared in $30.4 \times 18 \times 12.8 \mathrm{~cm}$ opaque polyethylene cages with wire-grid tops, wood-chip bedding, and nesting materials provided. The day after one on which at least 3 litters were born, pups were randomly cross-fostered to produce litter sizes of 6 and 16 , which provided the "normally nourished" and "undernourished" conditions, with equivalent numbers of pups of each gender within litters. Litters that contained fewer than 8 or more than 11 pups at birth were not used, nor were litters with newborn pups that appeared either smallor large-for-date. Mothers had ad-lib access to food and water and remained with the pups until weaning at 28 days of age. At weaning, pups were placed, with other like-sex age-mates of the same litter size, in the same-size cages in which they were born, and given ad-lib access to food and water for the duration of the study. The colony and test rooms, maintained at $24^{\circ} \pm 1^{\circ} \mathrm{C}$, were on a 12:12-h light:dark cycle that began at $0800 \mathrm{~h}$; all testing was carried out during the light cycle.

\section{Apparatus}

The apparatus consisted of a $23.5 \times 10 \times 14 \mathrm{~cm}$ automated twoway active-avoidance shuttlebox. The sides and top were Plexiglas, and the end walls were aluminum. The grid floor, constructed of 2-mmdiameter stainless steel rods spaced $7 \mathrm{~mm}$ center-to-center, was pivoted at the center so that it tilted slightly when the mouse moved $3 \mathrm{~cm}$ either side of center. Footshock, the unconditioned stimulus (UCS), was provided by a fixed-impedance shock source consisting of a 325-V transformer and a variable transformer in series with a $150-\mathrm{k} \Omega$ resistor. The shock level was set at $150 \mathrm{~V}$ and was transmitted through a BRS/LVE (SC-902) scrambler to the grid floor.

The shuttlebox was housed within a sound-attenuated chamber (48 $\times 48 \times 68.5 \mathrm{~cm}$ ) constructed of particle board, with acoustical tile lining the inside walls. Within the chamber, general illumination was provided by a $6-\mathrm{W}$ incandescent ceiling bulb and ventilation was provided by a squirrel-cage blower that produced a $74-\mathrm{dB}$ ambient noise level. A $10-\mathrm{cm}$ speaker was located in the uppermost, back left corner of the chamber and provided a $2.35-\mathrm{kHz}, 100-\mathrm{dB}$ tone from a BRS/Foringer audio generator (AU-902) as part of the compound light-tone conditional stimulus (CS). For the light CS, small light bulbs (General Electric 24ESB slidebase lamps) were mounted in the center of each end wall, $9.5 \mathrm{~cm}$ above the grid floor.

\section{Procedure}

Beginning at 60 days of age, 10 males and 10 females from each litter size were selected randomly so that no more than one male and one female represented each litter. Thus, each nutrition group was represented by 10 different litters. Original training consisted of 50 daily activeavoidance trials for 14 consecutive days (24-h intertest interval). No adaptation trials were given. The first trial on each day began with the mouse being placed into one side of the shuttlebox. About $60 \mathrm{sec}$ later, the compound light-tone CS was presented, followed by the addition of a shock UCS if the mouse failed to cross the chamber within $5 \mathrm{sec}$. The CS and UCS continued until either the mouse escaped to the other side of the chamber or a maximum latency period of $300 \mathrm{sec}$ had occurred. A successful avoidance, escape, or maximum latency trial was followed by a fixed intertrial interval (ITI) of $30 \mathrm{sec}$. Crossings during the ITI resulted in shock until the mouse escaped back to the safe side, but did not alter either the occurrence of trials or the length of the ITI. Following each subject's daily training session, the shuttlebox and the grid floor were cleaned with a damp cotton ball, and clean wood chips were placed in the pan beneath the grid floor. The shuttlebox and the grid floor were cleaned with alcohol following each day's testing.

Following the 14-day training session, the mice were left undisturbed until retention testing began 14 days later, when the mice were 88 days old. Retention testing was identical to original training, but was conducted over only 5 days. In addition to the previously trained mice, nontrained littermates ( 10 males and 10 females from each litter size) served as controls and received training at this time over the 5 consecutive days.

In addition to the numbers of successful avoidances made within each block of 10 trials, the daily total amount of ITI shock and the daily amount of UCS shock time within trials during each session were recorded for each subject. The amount of ITI shock should reflect the mouse's ability to inhibit crossing between trials, whereas the amount of UCS shock time should represent escape proficiency during each daily session. Body weights $(0.1 \mathrm{~g})$ were recorded on each test day.

\section{RESULTS}

Separate analyses of variance (after Winer, 1971) were conducted on the original training and retention data for each dependent measure. The major factors of each ANOVA were nutrition (litter size), gender, and days of testing. The ANOVAs for avoidance included the additional factor of trial blocks (five blocks of 10 trials); those for retention included the additional factors of trial blocks and training group (retest vs. controls).

\section{Original Training}

On the first day of avoidance training, following 32 days of postweaning ad-lib access to food and water, 6-litter mice weighed an average of $37.36 \mathrm{~g}$, whereas 16 -litter mice weighed $30.73 \mathrm{~g}$. Over all training days, 6-litter mice were significantly heavier than 16 -litter mice $[F(1,36)=58.88$, $p<.0005]$, and males from both litter sizes were approximately $6 \mathrm{~g}$ heavier than females $[F(1,36)=57.71$, $p<.0005$ ]. Over the 14 days of avoidance training, both litter sizes displayed comparable decreases in body weight of about $0.5 \mathrm{~g}[F(13,468)=7.04, p<.0005]$.

The mean numbers of successful avoidances made during original training for the two early nutrition groups are shown in the left panel of Figure 1 as a function of days of training. It is clear that the performance on early trials was comparable but quite poor for both litter sizes, each making about four avoidances out of 50 daily trials. Over the 14 training days, there was an overall increase in avoidances $[F(13,468)=20.94, p<.0005]$; however, the 6-litter mice showed more rapid improvement over days than did 16-litter mice, resulting in an overall main effect between litter size $[F(1,36)=7.42, p<.025]$, as well as nutrition $\times$ days interaction $[F(13,468)=2.77$, $p<.001]$. The 6-litter group made significantly more avoidances than the 16-litter group on the 3rd day of training and every day thereafter [all $F_{\mathrm{s}}(1,468)>6.45$, all ps $<.025$ ]. Within litter size, daily improvement from 


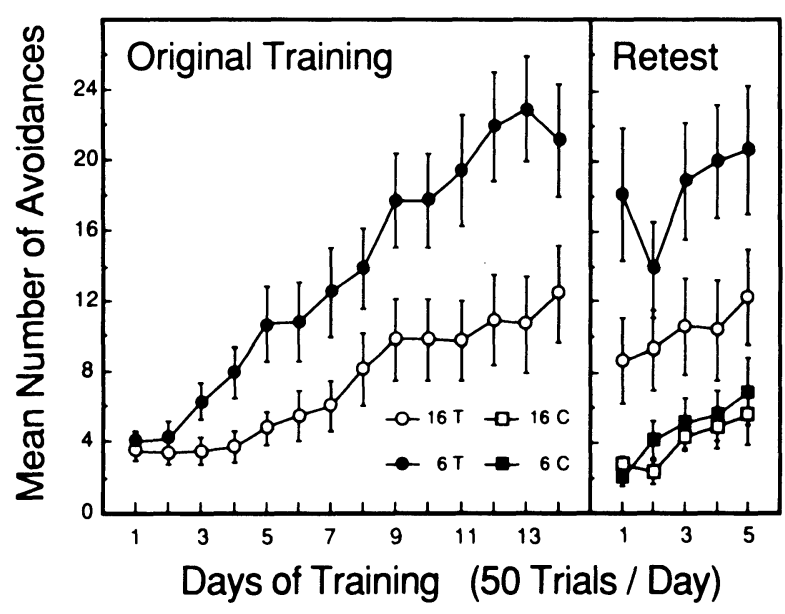

Figure 1. Mean numbers of avoidance responses made during original training and retention as a function of litter size and training group.

the 1st training day became significant for the 6-litter group by the 3rd training day $[F(1,468)=9.34, p<.005]$ and for the 16-litter group by the 6th day $[F(1,468)=$ $7.42, p<.01]$.

Although the main effect for trial blocks was significant $[F(4,144)=10.35, p<.0005]$, a reliable trial blocks $\times$ days interaction $[F(52,1872)=1.56, p<.01]$ reflected the fact that there was little overall within-session improvement on the first few training days, with greater amounts of improvement on later days. The failure to find a significant nutrition $\times$ days $\times$ trial blocks effect $[F(52,1872)=0.90, p>.50]$ indicated that the rates of within-session improvement for both litter sizes were comparable over training days. Since the nutrition $x$ days interaction was reliable, these results suggest that the poorer performance over days by the 16-litter group was due to poorer learning within days rather than to between-day or 24-h memory deficits.

Analysis of the ITI shock time showed only an overall decrease over test days $[F(13,468)=1.84, p<.05]$, from a mean of $25.52 \mathrm{sec}$ on Day 1 to $8.20 \mathrm{sec}$ on Day 14, suggesting that the mice from both nutritional conditions were learning to inhibit intertrial crossings at similar rates. Analysis of the amount of UCS time showed a decrease of mean total shock time from $180.85 \mathrm{sec}$ for 50 trials on Day 1 to $85.6 \mathrm{sec}$ on Day 14; however, this decrease was not statistically reliable. Neither analysis indicated any significant main effects of nutrition nor any interactions involving nutrition, suggesting that early undernutrition had little effect upon either escape performance or inhibition of intertrial crossings.

\section{Retention}

On the first day of retention testing, the mean body weights for the 6- and 16-litter groups were 39.71 and $33.14 \mathrm{~g}$, respectively $(p<.005)$. Although both litter sizes showed some weight gain from original training, the approximate weight difference of $6.6 \mathrm{~g}$ was maintained.
There were no reliable weight differences between the previously trained mice and their respective litter-size controls.

The right panel of Figure 1 depicts the mean numbers of avoidance responses made over the 5 days following the 2-week retention interval by the two trained groups and their respective controls. Planned comparisons with the nutrition $\times$ group interaction revealed that both previously trained groups made more avoidances than their respective controls $(p s<.05)$, that the 6-litter trained group made more avoidances than the 16-litter trained group $(p<.01)$, and that the two control groups failed to differ from each other.

Both litter sizes evidenced some decrease in the numbers of avoidances from the last training day to the first retest day, but $t$ tests for dependent measures indicated neither decrement to be reliable $[t \mathrm{~s}(19)=1.27$ and 1.91 , respectively, for 6 and $16, p s>.05]$.

A separate ANOVA conducted on the first 5 training days for the trained groups (60-64 days old) and for the controls (88-92 days old) indicated that the avoidance performance by the two litter sizes did not change appreciably from 60-88 days of age. Analyses of ITI and UCS shock times found no significant differences due to early nutrition or any interactions with that factor for either ITI or UCS shock times.

\section{DISCUSSION}

Our data demonstrate quite clearly that rearing mice in large litters during the early "brain growth spurt" results in a marked deficiency in active-avoidance behavior in later life. Although we cannot yet clearly attribute this deficiency to learning or performance variables or to direct or indirect effects of early undernutrition, our results do provide further evidence that the mouse may be a very useful subject to use in undernutrition research. Before one can attempt to answer these questions experimentally, one must have a reliable behavioral change with which to work. Our acquisition data are very consistent with those reported previously for the mouse (Castellano \& Oliverio, 1976; Leathwood, 1978; Leathwood et al., 1974) and suggest that the large-litter rearing technique can result in reliable, long-term behavioral deficiencies in an active-avoidance learning task, unlike the inconsistent results reported for the rat on this task (Guthrie \& Brown, 1968; Morris, 1974).

In contrast to undernutrition studies with the rat, our results indicated that males and females suffered equivalent deficiencies in body weight and active-avoidance performance because of some aspect of their being reared in large litters. If this lack of a gender difference is found for other learning and/or memory tasks, the mouse may prove to be a more efficient species to investigate than the rat, since both males and females can be used as subjects.

Finally, our results suggest that long-term memory is not affected by early rearing in large litters. Although the mice reared in small litters performed significantly better during the retention test than did both those reared in large litters and the nontrained controls, it was obvious that this difference resulted because the small-litter mice leamed or performed better during original training than did the large-litter mice. Compared with their performance at the end of original training, each litter-size showed similar retention. However, one must keep in mind that we have tested memory at only one retention interval, 2 weeks, and after a fixed amount of training. Differences in long-term memory might be evidenced if both nutrition groups had been trained to a common criterion during original training or if other, longer retention intervals had been tested. The few studies that have investigated long-term memory in rats that were rehabilitated after early undernutrition have been inconsistent (Celedon, Smart, \& Dobbing, 1982; Wetzel, Rüthrich, \& Matthies, 1979), although they have been interpreted as indicating some deficiency in long-term memory after early undernutrition (Smart, 1986). 
Overall, the present study indicates that consistent behavioral deficiencies are found in active-avoidance learning in mice that have been reared in large litters during the early suckling period. Although the large-litter technique has been criticized because of the marked changes it produces in mother-pup and pup-pup interactions, its use with the mouse may offer several advantages when it is compared with other undernutrition techniques. First, large-litter rearing, at least in rats, does not appear to produce either lowered food utilization efficiency or changes in the blood sugar response to glucose, as have been reported for other techniques (Hsueh, Blackwell, \& Chow, 1970; Roeder \& Chow, 1971). Second, Swiss mice are a robust strain with high fertility and appear better able than inbred strains to successfully nurse their litters through weaning, whether they themselves are undernourished or are rearing large litters (Leathwood et al., 1974). Third, the deficiencies in brain and body growth and reflex development, as well as active-avoidance learning and exploratory activity, are not overcome, even when the natural lactating mother is supplemented with two adult, nonlactating maternalized females to provide additional maternal care to the largelitter pups (Castellano \& Oliverio, 1976).

\section{REFERENCES}

BEDI, K. S. (1984). Effects of undernutrition on brain morphology: A critical review of methods and results. In D. G. Jones (Ed.), Current topics in research on synapses (pp. 93-163). New York: Alan R. Liss.

BEDI, K. S. (1987). Lasting neuroanatomical changes following undernutrition during early life. In J. Dobbing (Ed.), Early nutrition and later achievement (pp. 1-49). London: Academic Press.

BURNs, E. M. (1984). Some effects of malnutrition on synaptic systems: An integration of morphologic, neurochemical, and neurophysiologic data. In D. G. Jones (Ed.), Current topics in research on synapses (pp. 59-91). New York: Alan R. Liss.

Castellano, C., \& Oliverio, A. (1976). Early malnutrition and postnatal changes in brain and behavior in the mouse. Brain Research, 101, 317-325.

Celedón, J. M., Smart, J. L., \& Dobbing, J. (1982). Effects of level of motivation on visual discrimination, transfer of learning, and longterm memory in previously undernourished and control rats. Nutrition \& Behavior, 1, 89-97.

CRNIC, L. S. (1976). Effects of infantile undernutrition on adult learning in rats: Methodological and design problems. Psychological Bulletin, 83, 715-728.

DobBing, J. (1968). Vulnerable periods in developing brain. In A. N. Davison \& J. Dobbing (Eds.), Applied neurochemistry (pp. 287-316). Philadelphia: Davis.

Fleischer, S. F., \& TURKEWITZ, G. (1979a). Behavioral effects of rotation between lactating and nonlactating females. Developmental Psychobiology, 12, 245-254.

FleISCHER, S. F., \& TURKEWITZ, G. (1979b). Effect of neonatal stunting on development of rats; Large litter rearing. Developmental Psychobiology, 12, 137-149.

GuTHRIE, H. A., \& BRown, M. L. (1968). Effect of severe undernutrition in early life on growth, brain size and composition in adult rats. Journal of Nutrition, 94, 419-426.

HeRsChKowITZ, N. (1989). Brain development and nutrition. In P. Evrard \& A. Minkowski (Eds.), Developmental neurobiology (pp. 297-304). New York: Nestec \& Vevy/Raven Press.

Hsueh, A. M., Blackwell, R. Q., \& ChOW, B. F. (1970). Effect of maternal diet in rats on food consumption of the offspring. Journal of Nutrition, 100, 1157-1164.

JoRDAN; T. C., \& ClARK, G. A. (1983). Early undernutrition impairs hippocampal long-term potentiation in adult rats. Behavioral Neuroscience, 97, 319-322.

KATZ, H. B. (1980). The influence of undernutrition on learning per- formance in rodents. Nutrition Abstracts \& Reviews. Series A: Human \& Experimental, 50, 767-784.

KatZ, H. B., \& Davies, C. A. (1982). The effects of early-life undernutrition and subsequent environment on morphological parameters of the rat brain. Behavioural Brain Research, 5, 53-64.

LEATHWOOD, P. (1978). Influence of early undernutrition on behavioral development and learning in rodents. In G. Gottlieb (Ed.), Early influences (pp. 187-209). New York: Academic Press.

Leathwood, P., Bush, M., Berent, C., \& Mauron, J. (1974). Effects of early malnutrition on Swiss white mice: Avoidance learning after rearing in large litters. Life Sciences, 14, 157-162.

LEVINE, S., \& WiENER, S. (1976). A critical analysis of data on malnutrition and behavioral deficits. Advances in Pediatrics, 22, 113-136.

LEVITSKY, D. A., \& BARNES, R. H. (1970). Effect of early malnutrition on the reaction of adult rats to aversive stimuli. Nature, 225, 468-469.

MoRris, C. J. (1974). The effects of early malnutrition on one-way and two-way avoidance behavior. Physiological Psychology, 2, 148-150.

NowAK, T. S., JR., \& MUNRo, H. N. (1977). Effects of protein-calorie malnutrition on biochemical aspects of brain development. In R. J. Wurtman \& J. J. Wurtman (Eds.), Nutrition and the brain (pp. 193260). New York: Raven Press.

Plaut, S. M. (1970). Studies of undernutrition in the young rat; Methodological considerations. Developmental Psychobiology, 3, 157-167.

RoEDER, L. M., \& CHOw, B. F. (1971). Influence of the dietary history of test animals on responses in pharmacological and nutritional studies. American Journal of Clinical Nutrition, 24, 947-951.

SAlbeGo, C., \& SouZA, D. O. (1986). Effects of undernutrition during suckling on phosphoryl-serine levels in brain nuclear proteins of adult rats. Journal of Nutrition, 116, 2303-2310.

ShOemaker, W. J., \& BLOM, F. E. (1977). Effect of undernutrition on brain morphology. In R. J. Wurtman \& J. J. Wurtman (Eds.), Nutrition and the brain (pp. 147-192). New York: Raven Press.

SMART, J. L. (1977). Early life malnutrition and later learning ability: A critical analysis. In A. Oliverio (Ed.), Genetics, environment and intelligence (pp. 215-235). Amsterdam: Elsevier/North-Holland Biomedical Press.

SmarT, J. L. (1984). Undernutrition, learning and memory: A critical analysis. Clinical Neuropharmacology, 7(Suppl. 1), 358-359.

SMART, J. L. (1986). Undernutrition, learning and memory: Review of experimental studies. In T. G. Taylor \& N. K. Jenkins (Eds.), Proceedings of the XIII International Congress of Nutrition (pp. 7478). London: John Libbey.

SmarT, J. L., \& DobBING, J. (1977). Increased thirst and hunger in adult rats undernourished as infants: An alternative explanation. British Journal of Nutrition, 37, 421-430.

Smart, J. L., Whatson, T. S., \&obbing, J. (1975). Thresholds of response to electric shock in previously undernourished rats. British Journal of Nutrition, 34, 511-516.

WeTZEL, W., Rüthrich, H.-L., \& MATTHIES, H. (1979). Memory impairment in adult rats after postnatal undernutrition. Behavioral \& Neural Biology, 25, 157-165.

WiggiNs, R. C., FUller, G., \& ENNA, S. J. (1984). Undernutrition and the development of brain neurotransmitter systems. Life Sciences, 35, 2085-2094.

Willuams, J. P. G., Tanner, J. M., \& Hughes, P. C. R. (1974). Catchup growth in female rats after growth retardation during the suckling period: Comparison with males. Pediatric Research, 8, 157-162.

WINER, B. J. (1971). Statistical principles in experimental design (2nd ed.). New York: McGraw-Hill.

(Manuscript received February 19, 1991.) 